\title{
13 PLACENAMES IN YUWAALARAAY, YUWAALIYAAY AND GAMILARAAY LANGUAGES OF NORTH-WEST NEW SOUTH WALES
}

Anna Ash

\section{INTRODUCTION'}

Yuwaalaraay, Yuwaaliyaay and Gamilaraay are closely related languages that cover a large area of north-west New South Wales, from the New South Wales-Queensland border down to the Tamworth area, and from the edge of the Tablelands, west to beyond Walgett. Cognacy rates of around 60-80 per cent (Williams 1980:1) and comparable grammars mean that the three languages are dialects. The names of these languages have two parts, the first part is the word for 'no', and the second is the comitative suffix meaning 'having'. So Yuwaalaraay has yuwaal (actually waal) 'no', and Gamilaraay has gamil 'no'. This is a fairly common way of naming Aboriginal languages in this area; compare, for example, Yugambal of the Inverell area which has yuga 'no', and Wiradjuri from central-southern NSW which has wirray 'no'.'

During 1999 work began on the Yuwalaraay, Yuwaaliyaay and Gamilaraay dictionary database. The project involves creating a dictionary with and for the Yuwaalaraay, Yuwaaliyaay and Gamilaraay people. The author is compiling data from historical sources, ${ }^{3}$ from Yuwaalaraay, Yuwaaliyaay and Gamilaraay people, and from the checking of historical

1 This report comes from a work in progress, and while some information has been published by other people (as referenced), other information is still subject to further community consultation and revision. I would like to acknowledge the input of Uncle Ted Fields, Aunty Pearl Trindall and Uncle Jo Trindall, John Giacon, Peter Thompson, Meg Leathart and Tamsin Donaldson. Of course, any errors rest with the author.

2 Abbreviations used in this paper are: COM comitative; DIM diminutive; LOC locative; NONFUT non future; PRIV privative; REDUP reduplication.

3 Sources include tapes recorded by Corinne Williams and Janet Mathews (Yry, Yyy) and Stephen Wurm (Gry); Ian Sim's word list (Yyy); and Peter Austin's Web Dictionary (Gry). These are supplemented by Giacon (1998), Giacon and Sim (1998), Williams (1980) and many historical documents by people such as R.H. Mathews, Revs W. Ridley and C. Greenway, K. Langloh-Parker and M.J. Cain.

L. Hercus, F. Hodges and J. Simpson, eds, The Land is a Map: placenames of Indigenous origin in Australia, 181-185. Canberra: Pandanus Books in association with Pacific Linguistics, 2002.

(C) Anna Ash 
information with the people. The content and final form of publication ${ }^{4}$ will be determined by local Aboriginal people.

The current dictionary project is just one aspect of Yuwaalaraay (Yry), Yuwaaliyaay (Yyy) and Gamilaraay (Gry) language reclamation that also includes many school and community-based activities. The languages are taught in schools and Technical and Further Education (TAFE) courses for adults; Yuwaalaraay, Yuwaaliyaay and Gamilaraay language conferences are regularly held, bringing together Elders, teachers, community members and linguists to use language, share ideas and plan for further language reclamation. Local Aboriginal languages are increasingly being used in speeches, songs, naming, creative writing, and memorials, such as the recently opened Memorial to the Myall Creek Massacre of 10 June 1838 .

In the course of this work, names (so far, about 70) for places in the region have been incorporated into the database. These come from historical sources, other linguistic work and from Elders of the region, such as Uncle Ted Fields of Walgett who have a lot of valuable local knowledge. Analysis has begun on many other placenames that are potentially of Yuwaalaraay, Yuwaaliyaay or Gamilaraay origin; these are still to be checked with informants. Understandably, culturally sensitive information, such as placenames cited in Dreaming stories, are the subject of discussion as to whether or not they should be included in the dictionary.

It must be emphasised that this is a report on one section of a work in progress, the primary aim of which is to produce a dictionary that is useful across a wide region. The first step has been to concentrate on entering data from historical sources; while there has been some community consultation, the bulk of this is still to occur. The historical data therefore provide a base on which to build the current language knowledge, which may include significant variety across the region, and some words borrowed from languages outside the Yuwaalaraay, Yuwaaliyaay and Gamilaraay regions.

\section{FINDINGS}

Around 70 placenames have been analysed so far: of the four types described by Hercus and Simpson (this volume), the placenames range from those that describe aspects of topography and environment (such as landforms, trees, and animals) to those that refer to the activities of Ancestral Beings. In the following analysis reference will also be made to Hercus's classification (this volume) of placenames as 'generic', 'intermediate' and (perhaps) 'silly'.

Yuwaalaraay, Yuwaaliyaay and Gamilaraay placenames, as in many areas, often refer to events from dreamtime stories. Thus Bumaygarriya (Yyy) is a place on the Narran Lake, where Baayama 'the Creator' ambushed and killed the garriya 'crocodile'. The water gushing out of the body created Narran Lake (Giacon \& Sim 1998:26:App. 8). Note that syntactically it consists of a verb and its object:

\footnotetext{
The immediate goal is to produce a hard copy dictionary from the database, for use in local language programs. A FileMaker Pro database is being used, so that we can later produce other computer-based or on-line resources if the Yyr, Yyy and Gry communities so desire.

5 In this paper I have used the following conventions: when a placename is discussed as a name, it is given in italic; when a placename is mentioned as a place, it is given in plain type.
} 


\begin{abstract}
Buma-y garriya
kill-NONFUT crocodile

'Bumaygarriya'
\end{abstract}

Without the knowledge of Elders, placename analysis can be guesswork (albeit linguistically informed guesswork); the full meaning of a placename, for example, whether it refers to a landscape feature or a creation event may never be known. In north-west New South Wales, there are several Elders who have contributed knowledge to enable a fuller understanding of certain placenames. 'Cumborah $\mathrm{Knob}^{\prime}$ is a flat-topped hill that used to be known as Babarraa probably 'red and yellow snake' (Ted Fields pers. comm.), but perhaps from babarr- $a$ 'snake species-Loc' (author's analysis). Uncle Ted Fields tells the story of how it was originally a peaked hill, but two enormous snakes fought there; one threw its boomerang and sliced off the top of the hill. A place on the Narran River, near Angledool maluwil 'human shadow, spirit' (Yyy) - is so called 'because of the shadows there' (Giacon \& Sim 1998:24). In this case we may not have access to the full meaning of the name, for example, whether or not the site was connected to an Ancestral Being's journey.

Many of the current Yuwaalaraay, Yuwaaliyaay and Gamilaraay placenames based on flora, fauna and topography may be of the type that Hercus (this volume) classifies as 'generic' (that is, the use of a generic term where there may have been a specific term) or 'intermediate ... or descriptive'. Examples of generic placenames are Warrumbal (River) from Warrumbal (Yyy) 'watercourse' (but also a name for the Milky Way); and Burrul Gungan (Yyy) 'big water', which Sim was given as the name for Narran Lake (Giacon \& Sim 1998:App. 9).

Names that refer to topographic features include, in Gamilaraay: Boggabri, bagaay-baraay 'creek-COM', and Boggabila, Bagaay-bil-a 'creek-having many-LOC' (Austin 1993:2) and Milbulah, Mil-bil-a 'eye/hole-having many-LOC'; and Dandara, Dhandarr-a 'frost/ice-LOC' (author's analysis). In Yuwaaliyaay, Sim (1998) mentions Cowal, Gaawul 'creek, lagoon'; and two other as yet unknown locations: Garrabila, Garra-bilaa 'cracks-parallel' and Garradhuul, Garra-dhuul 'cracks-DIM'.

Many placenames refer to vegetation; in Gamilaraay there is Collarenabri, Galariin-baraay 'coolabah blossom-COM'; Tarilarai, Dhariil-araay 'reed-COM'; Drilldool, Dhariil-duul 'reed-DIM' (Austin 1993:2); and Gurley, gurralay 'river wattle' (O'Rourke 1995:95). Yuwaaliyaay placenames based on flora may include: Ngamanbirrabaa, Ngamanbirra-baa 'wild plum-LOC'; Brewarrina, possibly Birraa-warra-nhi 'whitewood tree-stand-NONFUT' (author's analysis); and Yerranbaa, Yaran-baa 'a type of acacia-LOC' (Ted Fields pers. comm.). Many of these placenames referring to vegetation may be classified as Hercus's 'intermediate' names.

Several placenames have been recorded that reflect the significance of the type of soil and rock of that country. Yuwaaliyaay provides the following examples: Nee-Nee, Nhii-Nhii 'charcoal-REDUP', reduplication often forms an adjective from a noun; and Goonoo, Gunu 'lime gypsum' (Giacon \& Sim 1998). Again, Sim's work with Yuwaaliyaay people in the 1950s provides some insight: 'Boggy Ridge' which was once known as Buggy Ridge, is perhaps from bagi 'white pipe clay' (Giacon \& Sim 1998:19).

Fauna are the source of several placenames in the region. In Gamilaraay there is Bundarra, Bandaarr-a 'kangaroo-LoC' (Austin 1993:4). From Yuwaaliyaay we have Ballone, baluun 'great egret' and Bollonbillion, Baluun-bilyan 'great egret-waterhole' (author's analysis). Dirrinbandi, Dhurrun-banda-y 'hairy caterpillars-going along in a line-NONFUT' (Giacon \& Sim 1998:12); and Coorigel, Guligal ‘beehive debris' (Giacon \& Sim 1998:11). However, as 
yet, it is not possible to say whether these names have a purely descriptive reference or are associated with Creation beliefs.

Still other placenames show the effect of colonisation: Yarraman 'horse' and Timbumburi

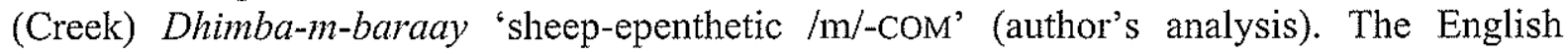
source of dhimba is thought by some to be jumbuck, however it could be a borrowing of 'sheep' with adaptation into Gamilaraay phonology and epenthetic $/ \mathrm{m} /$. This is in accordance with the fact that the word for sheep in some languages is dhimbak (Simpson pers. comm.) which would go to dhimba in Gamilaraay, as the language does not allow final $/ \mathrm{k} /$.

Coonabarabran is given the meaning 'inquisitive person' in Mary Jane Cain's 1920 (Gry) wordlist; this may be an example of Hercus's 'silly names' or, more precisely, the informant's way of avoiding giving a translation. It is not known whether 'inquisitive person' was Mrs Cain's response, or the response of an informant; however, there is nothing in the literature that supports this translation. It is more likely to be someone's polite way of not giving the true meaning which probably includes guna 'faeces' and perhaps also barabin 'semen'; compare also Coonamble Guna-m-bil 'faeces-/m/-having lots' (Gry, author's analysis).

There are several placenames which relate to body parts; although at this stage it is not certain whether they are metaphorical (compare English: Hungry Head, Hat Head) or whether they refer to Ancestral Beings. Giacon and Sim (1998:4) provide the following derivations for some Yuwaaliyaay placenames: Nullawa, Nguluu-wawul 'forehead/face-narrow', as in a narrow point of land going into a river; and Terewah (a branch of the Narran River), Dharrawawul 'leg-narrow'. There is also Angledool, Yanggal-dhuul 'vagina-small' (Giacon pers. comm.).

\section{RELATED ISSUES}

Placenames can contribute to knowledge about the boundaries between languages. For example, Gamilaraay does not permit final /ng/ (velar nasal), whereas a neighbouring language, Wiradjuri, does. Therefore places such as 'Wallumburrawang', 'Gowang Mountain' and 'Windurong' are likely to be outside Gamilaraay country. Similarly, places ending in the Wangaaybuwan and Wayilwan comitative suffix -buwan, such as 'Gulargambone', 'Quambone' and 'Mumblebone' are likely to be outside Gamilaraay country. Donaldson (1985:77) provides the full etymology of Gulargambone kilaampuwan as 'with young galahs'. Of course this kind of evidence is not firm proof of language boundaries, as the situation is complicated by borrowed or imported placenames.

An interesting example of the Elders' knowledge and historical records working together is the case of Narran (Lakes, River, Plains and Narrandool). There was nothing in recent recordings to hint at the meaning, and people said that they did not know the meaning of 'narran'. However a Gamilaraay Elder, Aunty Pearl Trindall, recalls that they used to call very skinny people 'narran gutted'; this is supported by Greenway (1911:85): 'Nerang or Noorong: small or nearer to, as opposed to the Coolgoa: not going so far round. The Aboriginal name of the river now called Narran'. We also have Williams' (Yry) recording of ngaarrigulay 'over here, this way', and Austin's (Gry) reconstruction from written sources, ngaariyalana 'this side of'. This is obviously not conclusive; there is some evidence for an interpretation of Narran (Nharran or perhaps Nharrang) as 'small', and some support for a kind of deictic 'here/this side'. This may be resolved if further evidence is found, otherwise it may be appropriate that Elders make a recommendation in the course of language reclamation. 
Finally, a single placename may occur in more than one country or language area; for example, there are several places named Wiidhalibaa 'wood/fire-PRIV'. In Yuwaalaraay country there is Weetaliba Waterholes (north-west of Lightning Ridge). In Gamilaraay country there is Weetaliba Station (south of Coonabarabran), and Weetalibah Creek (north of Coonamble). East of the Tablelands in Ngarrabul country there is also Wytalibah locality. (It is also the name of the station in Coonardoo by Katharine Susannah Prichard!) This is fairly common and may result from several factors including: high cognacy rate within the dialects; shared placenaming strategies across languages; and the non-Aboriginal tendency to take names with them when they move.

It is hoped that further research and consultation will fill some of the gaps in our current understanding of placenames in north-west New South Wales. While some derivations may remain 'best guesses', it is important that wherever possible, this linguistic analysis of placenames is informed by and checked with the Elders of the Gamilaraay, Yuwaalaraay and Yuwaaliyaay peoples.

\section{REFERENCES}

Austin, Peter, 1993, A Reference Dictionary of Gamilaraay, Northern New South Wales. Melbourne: La Trobe University, Department of Linguistics.

Austin, Peter and David Nathan, Kamilaroi/Gamilaraay web dictionary. On the internet at: http:/coombs.anu.edu.au/WWWVLPages/AborigPages/LANG/GAMDICT/GAMDICT.HTM \#2001.

Cain, Mary Jane, 1920, Names of places and their meanings in the native language. Unpublished word list.

Donaldson, Tamsin, 1985, Hearing the first Australians. In Ian Donaldson and Tamsin Donaldson, eds, Seeing the First Australians, 76-91. Sydney: George Allen and Unwin.

Giacon, John, ed., 1998, Yuwaalaraay/Gamilaraay Wordlist. Walgett: Walgett High School Yuwaalaraay-Gamilaraay Language Program.

Giacon, John, ed., and Ian Sim (recorder), 1998, Yuwaalayaay: the language of the Narran River. Walgett: Giacon.

Greenway, Rev. C.C., 1911, Aboriginal place names in the county of Benarba (cont.). Kamilari tribe. Science of Man 13(4):85.

O'Rourke, Michael, 1995, The Kamilaroi Lands: north-central New South Wales in the early 19 th century. Griffith, ACT: the author.

Williams, Corinne, 1980, A Grammar of Yuwaalaraay. Canberra: Pacific Linguistics. 